\title{
Management of dermal filler (vascular) complications using duplex ultrasound
}

Dear Editor,

The use of dermal fillers using hyaluronic acid injections has emerged in recent years. Although hyaluronic acid fillers in general have a good safety profile, the rate of complications will likely increase because of the expanding use of dermal fillers. These complications may be host or filler injection related. One of the most feared complications concerns intravascular injections of hyaluronic acid fillers leading to local skin necrosis, tissue degradation, or blindness. ${ }^{1-3}$ This topic has been
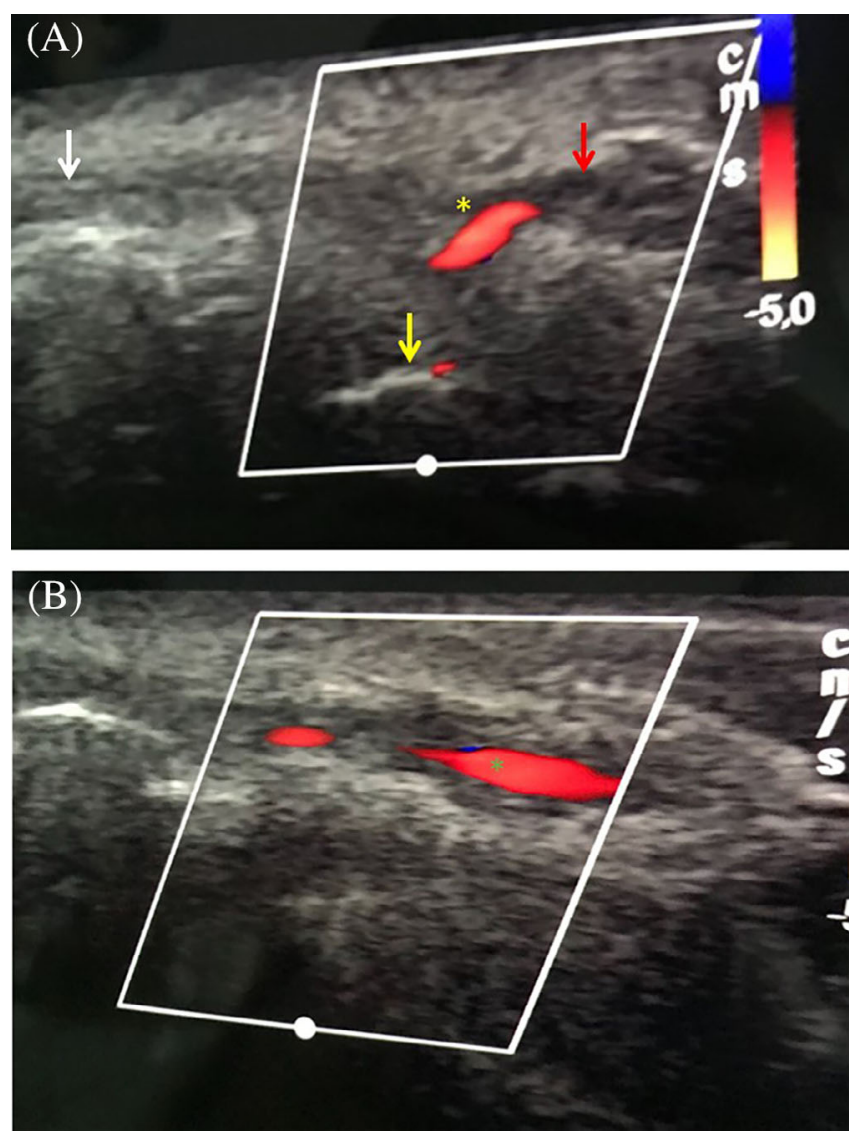

FIGURE 1 A, Duplex ultrasound image of a patient with partial occlusion of the superior labial artery. Orbicularis oris muscle (white arrow), teeth (yellow arrow), hyaluronic acid deposit (red arrow). The yellow asterisk shows part of the superior labial artery with impaired flow. B, Duplex ultrasound image of a patient with partial occlusion of the superior labial artery; 13 minutes after treatment with ultrasoundguided injection hyaluronidase, restoration of the flow was observed (green asterisk) broadly covered at the latest IMCAS Congress 2020 in Paris. An additional item in this regard is the use of duplex ultrasound to improve filler safety. ${ }^{4,5}$

The application of (duplex) ultrasound in cosmetic dermatology helps to determine the individual anatomy and map the vascular structures. When this mapping is done prior to the filler injection, chances for intravascular injections are minimized. In addition, previously placed fillers can be identified and complication of fillers accurately diagnosed. Dermal fillers containing hyaluronic acid are hydrophilic and show characteristic features. Basically, the ultrasound waves go through the water-containing filler, and ultrasound gives a black (anechoic) image when newly placed or a grayish (hypoechoic) view on the screen when the filler is longstanding. ${ }^{6}$ In patients with vascular occlusion, ultrasound color flow (duplex mode) helps to determine the area with no flow or turbulent flow indicating vessel obstruction.

In Figure 1A, we present one of our cases with occlusion of the superior labial artery who was managed at our filler complication clinic by ultrasound-guided (linear probe, $12 \mathrm{MHz}$ ) injections of hyaluronidase.

Other protocols for treating vascular occlusions aim to open up the end arteriae by flooding the affected area with the high dosage of hyaluronidase. ${ }^{7}$ Our protocol targets the causing filler fragments in the larger arteries with much lower dosages. The instant success of the treatment can be observed by a restored flow on duplex ultrasound (Figure 1B).

In conclusion, the use of duplex ultrasound may improve the safety of filler treatments and become an integral part in the current management arsenal of filler complications. Ultrasound-guided intralesional delivery of hyaluronidase (Figure 2 ) is an additional benefit, rendering treatment more precise.

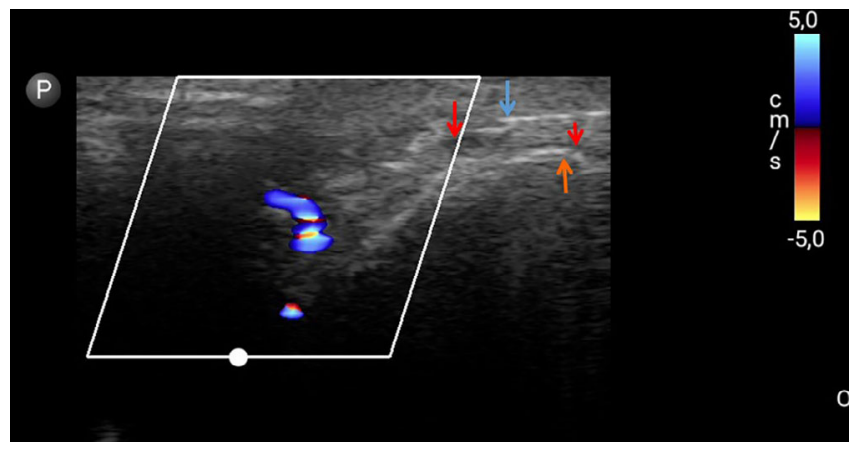

FIGURE 2 Duplex ultrasound image of a patient with occlusion of the supratrochlear artery. Hyaluronic acid deposit (red arrow), bone (orange arrow). The blue arrow points the needle through which hyaluronidase was injected in the hyaluronic acid deposit 


\section{CONFLICT OF INTEREST}

The authors declare no potential conflict of interest.

$$
\begin{aligned}
& \text { Sayed M. Habib }{ }^{1} \text { (D) } \\
& \text { Leonie W. Schelke }{ }^{2} \\
& \text { Peter J. Velthuis }{ }^{2}
\end{aligned}
$$

${ }^{1}$ Department of Dermatology, Leiden University Medical Center, Leiden,

The Netherlands

${ }^{2}$ Department of Dermatology, Erasmus MC, University Medical Center,

Rotterdam, The Netherlands

Correspondence

Sayed M. Habib, Department of Dermatology, Leiden University Medical Center, Albinusdreef 2, 2333 ZA Leiden, The Netherlands.

Email: habib.meelad@gmail.com

\section{ORCID}

Sayed M. Habib (iD) https://orcid.org/0000-0001-9582-5002

\section{REFERENCES}

1. Beleznay K, Carruthers JDA, Humphrey S, Carruthers A, Jones D. Update on avoiding and treating blindness from fillers: a recent review of the world literature. Aesthet Surg J. 2019;39(6): 662-674.

2. Park SW, Woo SJ, Park KH, Huh JW, Jung C, Kwon OK. latrogenic retinal artery occlusion caused by cosmetic facial filler injections. Am J Ophthal. 2012;154(4):653-662.e1.

3. DeLorenzi C. Complications of injectable fillers, part 2: vascular complications. Aesthet Surg J. 2014;34(4):584-600.

4. Schelke LW, Velthuis P, Kadouch J, Swift A. Early ultrasound for diagnosis and treatment of vascular adverse events with hyaluronic acid fillers. J Am Acad Dermatol. 2019. https://doi.org/10.1016/j.jaad.2019. 07.032 [Epub ahead of print].

5. Schelke LW, Decates TS, Velthuis PJ. Ultrasound to improve the safety of hyaluronic acid filler treatments. J Cosmet Dermatol. 2018;17(6): 1019-1024.

6. Schelke LW, Cassuto D, Velthuis P, Wortsman X. Nomenclature proposal for the sonographic description and reporting of soft tissue fillers. J Cosmet Dermatol. 2020;19(2):282-288.

7. Urdiales-Galvez F, Delgado NE, Figueiredo V, et al. Treatment of soft tissue filler complications: expert consensus recommendations. Aesthetic Plast Surg. 2018;42(2):498-510. 